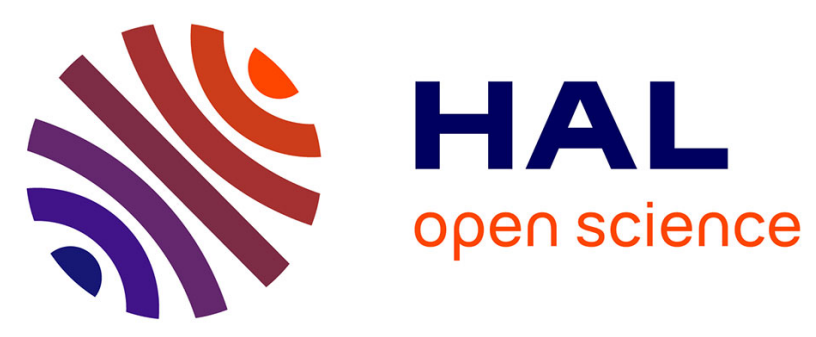

\title{
SEARCH FOR NARROW ISOVECTOR DIBARYONS CLOSE TO LOW MASSES THRESHOLD
}

\author{
B. Tatischeff, P. Courtat, Y. Le Bornec, E. Loireleux, F. Reide, N. Willis, O. \\ Bing, F. Hibou, M. Boivin, A. Moalem, et al.
}

\section{- To cite this version:}

B. Tatischeff, P. Courtat, Y. Le Bornec, E. Loireleux, F. Reide, et al.. SEARCH FOR NARROW ISOVECTOR DIBARYONS CLOSE TO LOW MASSES THRESHOLD. International Conference on Polarization Phenomena in Nuclear Physics, 1990, Paris, France. pp.C1-371-C1-374, 10.1051/jphyscol:1990631 。 jpa-00230898

\section{HAL Id: jpa-00230898 https://hal.science/jpa-00230898}

Submitted on 1 Jan 1990

HAL is a multi-disciplinary open access archive for the deposit and dissemination of scientific research documents, whether they are published or not. The documents may come from teaching and research institutions in France or abroad, or from public or private research centers.
L'archive ouverte pluridisciplinaire HAL, est destinée au dépôt et à la diffusion de documents scientifiques de niveau recherche, publiés ou non, émanant des établissements d'enseignement et de recherche français ou étrangers, des laboratoires publics ou privés. 
SEARCH FOR NARROW ISOVECTOR DIBARYONS CLOSE TO LOW MASSES THRESHOLD

B, TATISCHEFF, M.P. COMETS, P. COURTAT, Y. LE BORNEC, E. LOIRELEUX, F. REIDE, N. WILLIS, A.M. BERGDOLT T , G. BERGDOLT* ${ }^{*}$, O. BING* F. HIBOU ${ }^{*}$, M. BOIVIN* ${ }^{*}$ and A. MOALEM ${ }^{*},(1)$

Institut de Physique Nucléaire, F-91406 orsay Cedex, France "C.R.N., Université L. Pasteur, BP. 20, F-67037 Strasbourg Cedex. France

* Laboratoire National Saturne, CEN Saclay, F-91191 Gif sur Yvette, France

Résumé - Alors que pour des masses supérieures à $2 M_{N}+M_{\pi}$, l'existence de structures étroites isovectorielles dans les spectres de masses invariantes (manquantes) : $M_{\mathrm{pp}}$ $\left(M_{x}\right)$ est confirmé par 1 'apport des résultats de rouvelles expériences, il $n$ 'en est pas de même dans la région de masses inférieures à $2 M_{N}+M_{\pi}$. L'étude du pouvoir d'analyse tensoriel $T_{\mathbf{z} 0}$ de la masse invariante $M_{P p}$ a été entreprise à 1 'aide de la réaction $\mathrm{p}(\overrightarrow{\mathrm{d}}, \mathrm{pp}) \mathrm{x}$. Il apparaît un creux -ou une oscillation à $\mathrm{M}_{\mathrm{pp}}=1941 \mathrm{MeV}$ dont le degré de confiance dépend fortement de 1 'hypothèse concernant le fond. L'analyse en cours de données supplémentaires permetra d'améliorer la précision statistique.

Abstract - For masses larger than $2 M_{N}+M_{\pi}$, narrow peaks in two proton invariant (missing) masses spectra $: M_{p p}\left(M_{x}\right)$ are now well established. The existence of such narrow peaks is not so unquestionable below $2 M_{N}+M_{\pi}$. Tensor analyzing power $T_{2} 0$ of the invariant mass $M_{p p}$ has been studied using the $p(\vec{d}, p p) x$ reaction. Depending on the assumption done for background substraction -a hole or an oscillation may appear at $M_{p p}=1941 \mathrm{MeV}$. Additional data are under analysis and will improve the statistics.

It is well known that narrow structures have been observed in two nucleon invariant masses, or missing mass experiments/1/. These structures have been tentatively attributed to isovector dibaryons although no proof has been advanced to associate them with quark degrees of freedom. This assumption relies only on the fact that such structures are not present in classical nuclear physics using meson exchanges and nucleon or delta degrees of freedom.

The experimental certainty depends mainly on the quantum numbers and the mass of studied dibaryons. Up to now, none has been observed in $T=0 / 2 /$ or $T=2 / 3 /$ isospin states. In case of $T=1$ isospin, for the range of masses larger than $2 M_{N}+M_{\pi}(M>2.016 \mathrm{GeV})$ there is a good agreement for narrow peaks between results obtained at Saturne/4/: measurement of $\mathrm{d}^{2} \sigma / \mathrm{d} \Omega \mathrm{dM}_{\mathrm{x}}$ for ${ }^{3} \mathrm{He}(\mathrm{p}, \mathrm{d}) \mathrm{X}$ reaction, and Lampf/5/ where Ay was measured. These data correspond to the second generation of experiments, since they have used electronical detectors.

(1) Present address : Ben Gourion University of the Negev, P.0. Box 653 84105 Beer Sheva, Israel. 
Below $2.016 \mathrm{GeV}$, many structures have been presented, corresponding usually -but not alwaysto the first generation of experiments studying bubble chamber pictures. Here the masses of experimentally observed structures do not concentrate around a few values, but are more or less distributed from $2 \mathrm{M}_{N}$ to $2 \mathrm{M}_{N}+\mathrm{M}_{\pi} / 1 /$. The necessity of a precise second generation experiment close to the two nucleon mass appears then naturally.

Such an experiment has been carried out at SATURNE with the $\mathrm{p}(\overrightarrow{\mathrm{d}}, \mathrm{pp}) \mathrm{X}$ reaction. Tensor polarized deuteron beam of $1.722 \mathrm{GeV}$ has been used and the two protons detected at $0^{\circ}$ using the SPES 3 facility. The properties of the spectrometer : $\mathrm{p}_{\max } / \mathrm{p}_{\min } \approx 2.5$, and $\Delta \Omega=10^{-2} \mathrm{sr}$ allow the study of the following two proton invariant mass range : $2 \mathrm{M}_{\mathrm{N}}<\mathrm{M}_{\mathrm{pp}}<1.963 \mathrm{GeV}$, the counting rate decreasing regularly from small to larger masses $M_{p p}$. This result is mainly due to pP FSI giving rise to a narrow maximum a few $\mathrm{MeV}$ above $2 \mathrm{M}_{\mathrm{p}}$. Due to the granularity of the detection, when two trajectories intercept a same scintillator of one among the two major trigger detection plans or give rise to two mixing tracks on the focal plane, the event is 1ost. This produces a loss of efficiency in the first three MeV of the spectra.This explains that our FSI is located around $1880.7 \mathrm{MeV}$, that is $\approx 3 \mathrm{MeV}$ higher than the peak maximum from low energy experiments. The detection has been described elsewhere/3/. The empty target accounts for about $5 \%$ of the counting rate. The FWHM of the experimental width for $M_{p p}$ is $1.2 \mathrm{MeV}$. The data have been therefore binned into $2 \mathrm{MeV}$ intervals. The $\mathrm{M}_{\mathrm{pp}}$ histogram presented in Fig. 1 is quite continuous, without any discontinuity having a number of standard deviations (S.D.) larger than 2.2 .

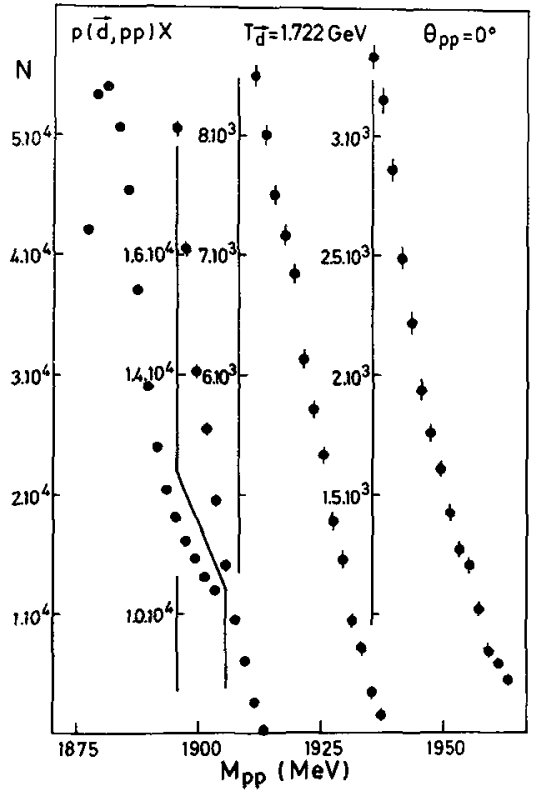

Fig. 1 : Histogram of two proton invariant mass $\mathrm{M}_{\mathrm{Pp}}$.

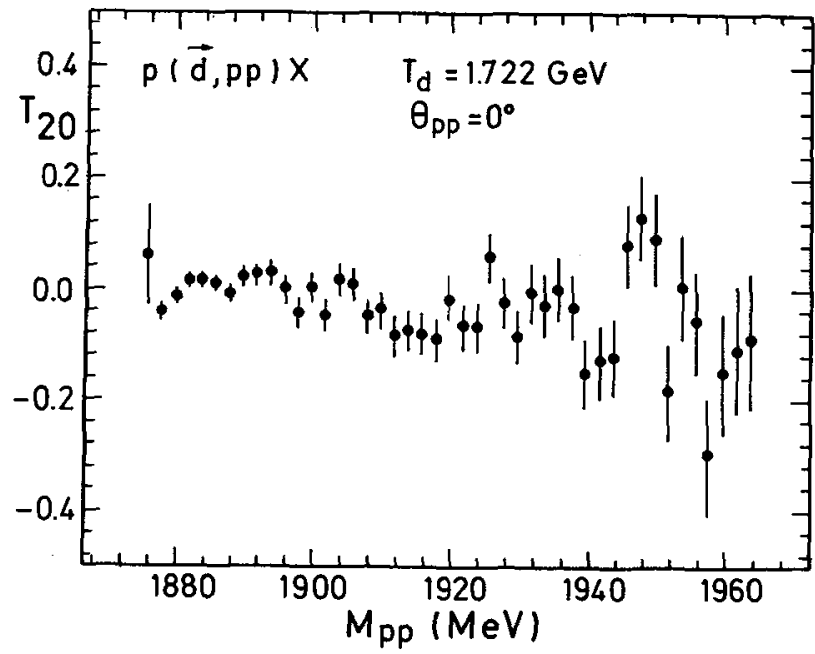

Fig. 4 : Tensor analyzing power as a function of two proton invaxiant mass. 
The deuteron polarized source, the formalism and the low energy polarimeter have been described previously/6/. The beam tensor polarization measured using a low energy polarimeter and $\mathrm{dd} \rightarrow$ pt reaction at $400 \mathrm{keV}$ was $\rho_{20}=0.61 \pm 0.03$, in agreement with values usually obtained/7/. The combination of the four states of polarization allows to get three tensor asymmetries. The first one $A_{N}$ should be zero. This has been checked -see Fig. 2. The second one, $A_{v}$, the vector asymetry leads to vector analyzing power $i T_{11}=\frac{1}{\rho_{10}} \sqrt{2} A_{v}$ where $\rho_{10}$ is the beam vector polarization. Since the measurements have been made at $0^{\circ}$, this analyzing power too should be zero within statistics. This has been checked -see Fig. 3. The tensor asymmetry $A_{T}$ is equal to $A_{T}=\frac{\rho_{20}}{2}\left(T_{20}(\theta)+\sqrt{6} T_{22}(\theta) \cos (2 \phi)\right)$. For $T_{22}(\theta)$, its value is formally equal to zero at zero degree but due to finite solid angle opening $( \pm 50 \mathrm{mrad}$ in both

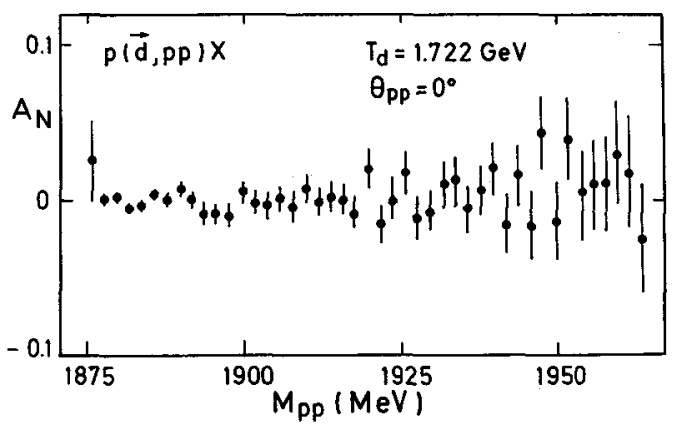

Fig. 2 : Zero tensor asymmetry as a function of two proton invariant mass.

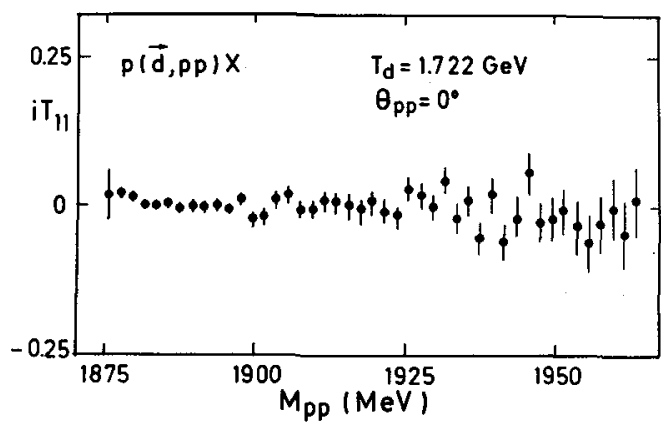

Fig. 3 : Vector analyzing power as a function of two proton invariant mass.

directions) and different beam emittances in vertical and horizontal directions, $T_{22}(\theta)$ $\cos (2 \phi)$ can be different from zero. We however write -since there is no theoretical calculation up to now and for the sake of simplicity $T_{20}=\frac{2}{\rho_{20}} A_{T}$. Neglecting the error on $\rho_{20}$ which acts on the whole spectrum, we get $\Delta \mathrm{T}_{20}=2 / \rho_{20} \Delta \mathrm{A}_{\mathrm{T}}$ where $\Delta \mathrm{A}_{\mathrm{T}}=$ $\left(1-\mathrm{A}_{\mathrm{T}}^{2}\right)^{1 / 2} \frac{1}{\sqrt{\mathrm{N}_{\mathrm{T}}}}$ and $\mathrm{N}_{\mathrm{T}}$ the total number of events per bin.

The data obtained for $\mathrm{T}_{20}$ are plotted on Fig. 4, where we can observe either a narrow hole at $\mathrm{M}_{\mathrm{pP}}=1941 \mathrm{MeV}$ ( $\mathrm{FWHM} \approx 6 \mathrm{MeV}$ ) either an oscillation around $1944 \mathrm{MeV}$ which would correspond to a coherent interaction between a resonance and background. The $T_{20}$ for the corresponding missing mass $M_{x}$ does not show such an oscillation. As usually we define the S.D. by using $\Delta \sigma_{T}^{2}=2 . \Delta \sigma^{2}$ measured. In spite of the present statistics, if we make the assumption of a hole at $1941 \mathrm{MeV}$, and a smooth background joining the data at both sides, we get S.D. $\approx 4.3$. However the normalized $\chi^{2}:\left(\chi^{2}{ }_{\text {tot }} /\left(N_{\text {data }} n_{\text {parameters }}\right)\right.$ for a third degree polynomial ( 5 parameters) is only improved from 1.56 to 1.36 when these seven data corresponding to the oscillation are removed. It seems therefore that any conclusion would be premature. We expect that the situation will be clarified after the completion of the analysis of new data on the same reaction at $T_{d}=2.1 \mathrm{GeV}$ and $\theta_{\mathrm{pp}}=17^{\circ}$. 
In the same $M_{p p}$ range, there are positive signals recently presented at nearly the same masses, both after bubble $c^{2}$ amber slides analysis :

- in a new compilation of $\mathrm{np} \rightarrow \mathrm{pp} \pi^{+}$and $\mathrm{np} \rightarrow \mathrm{pp} \pi^{-} \pi^{\circ}$ Troyan et a1/8/ have found a narrow peak at $\mathrm{M}_{\mathrm{Pp}}=1937 \mathrm{MeV}$

- in a recent publication presenting results from dp $\rightarrow$ ppn reaction, Glagolev et al.y9/ have found a narrow peak at $\mathrm{M}_{\mathrm{pp}}=1939 \mathrm{MeV}$. In both cases the number of S.D. using the assumption recalled before, are of the order of 2.2 .

A recent calculation from Arbuzov et al./10/ suggest a common explanation to pp narrow resonances and to $\mathrm{e}^{+} \mathrm{e}^{-}$GSI narrow resonances. They both will be a consequence of non-perturbative effects inside conventional QED. This calculation predicts $31, \mathrm{~L}=0$ resonances inside the mass range studied in our experiment. It does not predict the widths neither their expected relative excitation.

In conclusion, a structure around $1940 \mathrm{MeV}$ is possible, however its definition is not strong enough up to now.

\section{REFERENCES}

11/ Comets, M.P. et a1., Proceedings of $3 \mathrm{rd}$ International Conference on Hadron Spectroscopy, Ajaccio 1989, published by Editions Frontières Willis, N. et al., Comptes rendus des Sèmes journées d'Etude Saturne, Piriac, mai 1989, p. 39 ; Proceedings of the 5 th French-Japanese Symposium on Nuc1. Phys., Dogashima, 1989, p. 319 Tatischeff, B. et al., Proceedings of the IX International Seminar on High Energy Physics Problems, Dubna 1988, p. 317 ;

Nuc1. Phys. A446(1985)355C.

/2/ Combes, M.P. et a1., Nuc1. Phys. A431(1984)703.

/3/ Willis, N. et a1., Phys. Lett. B229(1989)33; Comets, M.P., Thesis 1989, University of Paris-Sud.

$14 /$ Tatischeff, B. et al., Phys. Rev. Lett. 52(1984)2022 ;

Europhysics Letters 4 (1987)671; 2. Phys. A - Atomic Nuclei $328(1987) 147$; Phys. Rev. C36(1987)1995.

/5/ Santi, L. et al., Phys. Rev. C38(1988) 2466.

16/ Arvieux, J. et al., Nucl. Phys. A431(613).

17/ Boudard, A. et a1., Phys. Lett. B214 (1988)1.

18/ Troyan, Yu. A. et a1., Dubna preprint P1-90-78 and P1-90-79, in russian.

19/ Glagolev, V.V. et al., Journal of Nuclear Physics 51(1990)736, in russian.

/10/ Arbuzov, B.A. et a1., Phys. Lett. B240(1990)477. 